\title{
Anabases
}

ANABASES Traditions et réceptions de l'Antiquité

$11 \mid 2010$

Varia

\section{Alexandra TRACHSEL, La Troade: un paysage et son héritage littéraire. Les commentaires antiques sur la Troade, leur genèse et leur influence}

Sylvie Rougier-Blanc

\section{OpenEdition}

\section{Journals}

Édition électronique

URL : http://journals.openedition.org/anabases/916

DOI : 10.4000/anabases.916

ISSN : 2256-9421

Éditeur

E.R.A.S.M.E.

Édition imprimée

Date de publication : 1 mars 2010

Pagination : 284-286

ISSN : 1774-4296

\section{Référence électronique}

Sylvie Rougier-Blanc, "Alexandra TRACHSEL, La Troade: un paysage et son héritage littéraire. Les

commentaires antiques sur la Troade, leur genèse et leur influence ", Anabases [En ligne], 11 | 2010, mis en ligne le 01 septembre 2011, consulté le 22 septembre 2020. URL : http://journals.openedition.org/ anabases/916 ; DOI : https://doi.org/10.4000/anabases.916

Ce document a été généré automatiquement le 22 septembre 2020

(c) Anabases 


\title{
Alexandra TRACHSEL, La Troade : un paysage et son héritage littéraire. Les commentaires antiques sur la Troade, leur genèse et leur influence
}

\author{
Sylvie Rougier-Blanc
}

\section{RÉFÉRENCE}

Alexandra TRACHSEL, La Troade : un paysage et son héritage littéraire. Les commentaires antiques sur la Troade, leur genèse et leur influence, Bâle, Schwabe, 2007, Bibliotheca Helvetica Romana 28, xx + 501p., schéma et 4 cartes en annexe 40, 50 euros / ISBN 9783796522543.

1 Alexandra Trachsel, membre de l'institut suisse de Rome, publie la thèse de doctorat qu'elle a préparée sous la direction du Professeur P. Schubert et qu'elle a soutenue en avril 2005 à l'université de Neuchâtel. Elle avoue (p. XX, n. 11) ne pas avoir pu y intégrer toutes les dernières nouveautés homériques, (souvent très nombreuses!), notamment les données de Joachim Latacz (curieusement cité dans la traduction anglaise et non dans l'édition originale de 2001), ce qui est regrettable.

2 Son ouvrage, doté d'une riche bibliographie, d'indices locorum et toponymiques très utiles, traite des différentes perceptions de l'espace littéraire de la Troade chez les lecteurs antiques d'Homère. Avec une approche diachronique (d'Hellanicos aux auteurs de la seconde sophistique, c'est-à-dire du IV ${ }^{e}$ s. av.J.-C. aux II ${ }^{e}-{ }^{-I I I}{ }^{e}$ s. ap. J.-C.) A.T. analyse les modifications des interprétations du paysage troyen, de la localisation de l'espace homérique ou de l'espace littéraire de la Troade. Organisé en deux parties et en quatre chapitres, l'ouvrage propose plus particulièrement d'éclairer les débats qui agitaient les Anciens sur l'identification de l'espace homérique à la Troade réelle et 
démêle notamment les facteurs politiques et historiques à l'origine du choix de telle ou telle interprétation sur la Troade.

3 Comme il se doit, la première partie (chapitre 1, p. 3-127) est consacrée à la Troade de l' Iliade. C'est peut-être la partie la plus décevante car, prise par les nécessités de son sujet (les interprétations postérieures de ce paysage littéraire), A. T. ne propose pas de véritable analyse d'ensemble du paysage homérique. Cette partie fait plutôt office d'introduction aux chapitres suivants. Cependant, avec une méthode très sûre, elle s'applique à recenser les repères topographiques et à dessiner « l'espace littéraire de la Troade homérique » qu'elle distingue de la Troade historique ou réelle. Sans répondre vraiment à la question que se posèrent les Anciens et qui taraude toujours les Modernes, - la Troade homérique est-elle pure fiction ou se réfère-t-elle à un paysage réel ?-, car elle choisit d'évacuer d'emblée la question homérique, A. T. donne corps à l'espace littéraire de la Troade d'Homère : un premier cercle délimité de part et d'autre par la ville de Troie et le campement achéen, deux pôles qui s'opposent et se complètent à la fois, est constitué par la plaine de Troie, le second cercle par les villes troyennes et les observatoires de dieux (Samothrace et le mont Ida marquant les extrémités). Les éléments qu'elle prend en considération pour analyser l'espace décrit (le point de vue du narrateur, la perspective à vol d'oiseau ou la perspective hodologique...) ouvrent la voie à une analyse plus poussée de la spatialité chez Homère qui dépasse le propos de l'ouvrage et qui reste à faire.

4 A. T. s'intéresse au premier chef à la postérité du paysage littéraire de la Troade. Elle aborde dans un premier temps les auteurs de l'époque hellénistique, voire même avant, avec Hellanicos de Lesbos et Palaïphatos (chapitre 2, p.131-283). Elle distingue les Troika, ou textes relatifs à la Troade, des textes à vocation plus scientifique (des fragments de Démétrios de Scepsis et de Polémon d'llion), et des textes poétiques (Apollonios de Rhodes, Callimaque Théocrite, Lycophron et Nicandre de Colophon). Dans les écrits scientifiques, les auteurs hésitent dans l'identification des espaces homériques avec la géographie de l'Asie Mineure et ne sont pas toujours capables de distinguer l'espace mythologique hérité d'Homère des précisions topographiques. La Troade réelle apparaît peu. Les poètes hellénistiques concilient plusieurs versions de l'espace littéraire troyen (ils se réfèrent au cycle troyen et non seulement à Homère) sans préférer une identification à une autre. L'impact des conquêtes d'Alexandre sur la perception de la Troade comme le développement des bibliothèques d'Alexandrie et de Pergame ne sont certes pas négligeables mais pour A.T. l'époque hellénistique se caractérise par une hésitation dans l'identification du paysage de la Troade.

Pendant l'époque romaine, objet du troisième chapitre (Rome et la Troade, p. 285-383), le paysage troyen est exploité aussi bien par les auteurs grecs ( Diodore de Sicile, Denys d'Halicarnasse, Strabon et Héraclite dans les Quaestions homericae) que latins (Virgile, Lucain, Ovide, Pomponius Méla). La Troade historique et réelle est désormais considérée, en raison de la réactivation des origines troyennes de Rome, principalement sous l'impulsion augustéenne. Il s'agit de retrouver les traces de la migration d'Enée en Italie et tous les auteurs latins (même Lucain) se conforment à la version officielle: Ilion est toujours Troie. Les auteurs grecs sont en revanche plus réticents et utilisent encore plusieurs versions sur la localisation de Troie. Ils n'adhèrent à la vision romaine qu'après de nombreuses discussions. Pour les Grecs comme pour les Latins, le texte homérique et le cycle troyen sont cependant toujours le point de départ de la réflexion sur la Troade. Virgile notamment ne s'inspire pas du 
paysage historique et réel de la Troade dans l'Enéide, mais crée « un pendant romain à l'épopée homérique» (p. 361).

6 La période de la seconde sophistique (chapitre 4, p. 385-458) marque une nouvelle étape avec «la révision d'Homère »: les fragments du mythographe homérique montre que les auteurs de la seconde sophistique cherchent souvent à contredire l'autorité d'Homère. Ils inventent parfois de manière ludique de nouveaux toponymes comme le fait Darès (p. 410-418). A. T souligne que, pendant cette période, le paysage réel de la Troade est beaucoup plus présent et rapproche ce phénomène du regain d'intérêt pour le passé proprement grec et du développement du tourisme à Ilion (p. 385-391). Chez les auteurs remaniant la légende troyenne, (notamment Dion Chrysostome), ou chez les géographes comme Pausanias, qui ont probablement visité la Troade, le paysage réel prend une place de premier plan.

7 L'ouvrage d'A. T. clair et bien construit offre un panorama stimulant sur près de sept siècles. L'auteur maîtrise la plupart du temps les données historiques et les multiples productions des auteurs dont elle prend soin de traduire les passages cités avec beaucoup de précision. Elle démontre de façon convaincante comment, au gré des enjeux politiques du moment, la Troade a été considérée tantôt comme un paysage littéraire, tantôt comme un espace réel et comment ces deux aspects se sont articulés chez les nombreux auteurs qu'elle analyse.

\section{AUTEURS}

\section{SYLVIE ROUGIER-BLANC}

Université de Toulouse (UTM)

srougier-blanc@neuf.fr 